\title{
The Splendore-Hoeppli phenomenon in hepatic botryomycosis
}

\author{
David Schlossberg, Manoj Pandey, Rajender Reddy
}

\begin{abstract}
A 68 year old diabetic man developed septicaemia and multiple liver abscesses due to Streptococcus intermedius. Liver biopsy revealed streptococcal botryomycosis which showed the Splendore-Hoeppli phenomenon. Diabetes mellitus is an example of the immunosuppressed states that have been associated with botryomycosis.

(F Clin Pathol 1998;51:399-400)
\end{abstract}

Keywords: Splendore-Hoeppli phenomenon; immunosuppression; streptococcal botryomycosis

The Splendore-Hoeppli phenomenon describes eosinophilic deposits that surround certain fungi, parasites, and bacterial colonies. We recently observed this formation around botryomycotic granules in liver abscesses caused by Streptococcus intermedius.

Department of

Medicine, Episcopal

Hospital, Philadelphia,

Pennsylvania, USA

D Schlossberg

M Pandey

R Reddy

Correspondence to:

Dr David Schlossberg,

Episcopal Hospital, 100 E

Lehigh Avenue, Philadelphia, PA 19125, USA.

Accepted for publication 30 January 1998

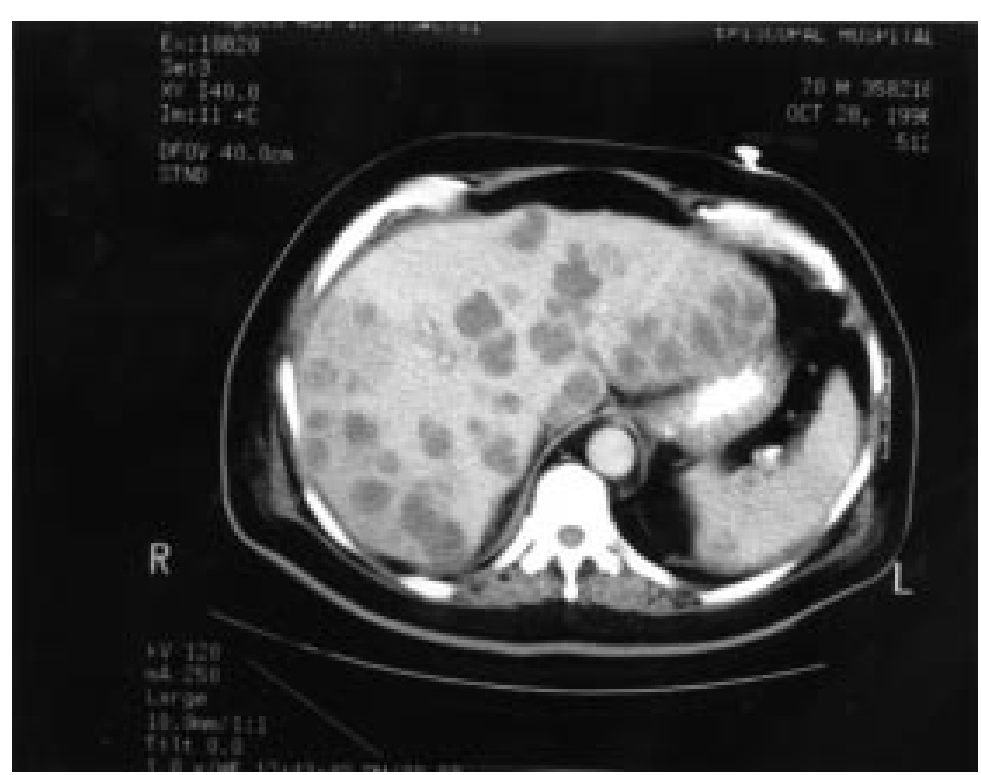

Figure 1 Abdominal computerised tomography with multiple low density lesions throughout the liver.

\section{Case report}

A 68 year old white male developed weight loss, polydipsia, polyphagia, and polyuria. Two weeks later he noted malaise, lightheadedness, and diarrhoea. His symptoms progressively worsened up to the day of presentation, when he became lethargic and disoriented. $\mathrm{He}$ denied headaches, cough, fever, chills, nausea, or vomiting.

He gave no history of illness apart from hypertension, for which he took triamterene. Up to three years ago he had smoked 40 packs of cigarettes a year, but since then he had stopped smoking. He drank heavily between 18 and 21 years of age. He denied intravenous drug abuse. He served in the Korean war but had not travelled abroad since then. He had owned a healthy dog for the past eight years.

On physical examination the patient was lethargic. Temperature was $96.0^{\circ} \mathrm{F}\left(35.6^{\circ} \mathrm{C}\right)$, blood pressure $130 / 70 \mathrm{~mm} \mathrm{Hg}$, pulse $112 / \mathrm{min}$, and respiratory rate $32 / \mathrm{min}$. Fundoscopic examination was normal. Neck was supple with no adenopathy. Lungs had decreased breath sounds at both bases, without wheezes or crackles. Heart sounds were normal with no murmur or rub. Abdomen was soft with slight tenderness in the right upper and left upper quadrants and hypoactive bowel sounds. Liver edge was palpable $3 \mathrm{~cm}$ below the right costal margin. Extremities showed good peripheral pulses with no oedema. There were no rashes or other skin lesions. Neurological examination revealed lethargy but was otherwise within normal limits.

Sodium was $143 \mathrm{mmol} / \mathrm{l}$, potassium 2.8 $\mathrm{mmol} / 1$, blood urea nitrogen $20.5 \mathrm{mmol} / 1$, creatinine $159.1 \mu \mathrm{mol} / 1$, serum glucose 53.8 $\mathrm{mmol} / \mathrm{l}$, and anion gap $31 \mathrm{mmol} / \mathrm{l}$. Protein was $6.0 \mathrm{~g} / \mathrm{dl}$, albumin $2.9 \mathrm{~g} / \mathrm{dl}$, calcium 2.43 $\mathrm{mmol} / \mathrm{l}$, urate $0.82 \mathrm{mmol} / \mathrm{l}$, cholesterol 4.2 $\mathrm{mmol} / \mathrm{l}$, total bilirubin $18.8 \mu \mathrm{mol} / \mathrm{l}$, alkaline phosphatase $288 \mathrm{U} / 1$, lactate dehydrogenase $1064 \mathrm{U} / 1$, aspartate transaminase $224 \mathrm{U} / 1$, lipase $1110 \mathrm{U} / 1$, and serum acetone 30-40 U/1. White blood cell count was $11 \times 10^{9}$ cells $/ 1$, haemoglobin $17.3 \mathrm{~g} / \mathrm{dl}$, packed cell volume $51 \%$, and platelet count $232 \times 10^{9} / 1$. Prothrombin time was $14.1 \mathrm{~s}$, international normalised ratio 1.2 , and partial thromboplastin time $40 \mathrm{~s}$. Arterial blood gases showed $\mathrm{pH} 7.35, \mathrm{PCO}_{2}$ $3.21 \mathrm{kPa}, \mathrm{PO}_{2} 16.7 \mathrm{kPa}$, and $\mathrm{O}_{2}$ saturation $98.9 \%$. Urinalysis was clear, with a specific gravity of $1.010, \mathrm{pH} 5.0$, ketones $1+$, and glucose $1000 \mathrm{mg} / \mathrm{dl}$. Initial chest $x$ ray was normal.

The patient was admitted with the diagnosis of diabetic ketoacidosis. An ultrasound of the abdomen revealed an enlarged and inhomogeneous pancreas with multiple masses in the liver. Abdominal computerised tomography (CT) (fig 1) showed multiple low density lesions throughout the liver, with a small amount of perihepatic fluid and minimal ascites. An ultrasound guided liver biopsy revealed focal granules of Gram positive cocci in an erythematous matrix (fig 2). Both the liver biopsy and blood cultures grew Streptococcus intermedius.

He was started on intravenous ampicillin/ sulbactam. Transoesophageal echocardiogram did not indicate any evidence of endocarditis. 


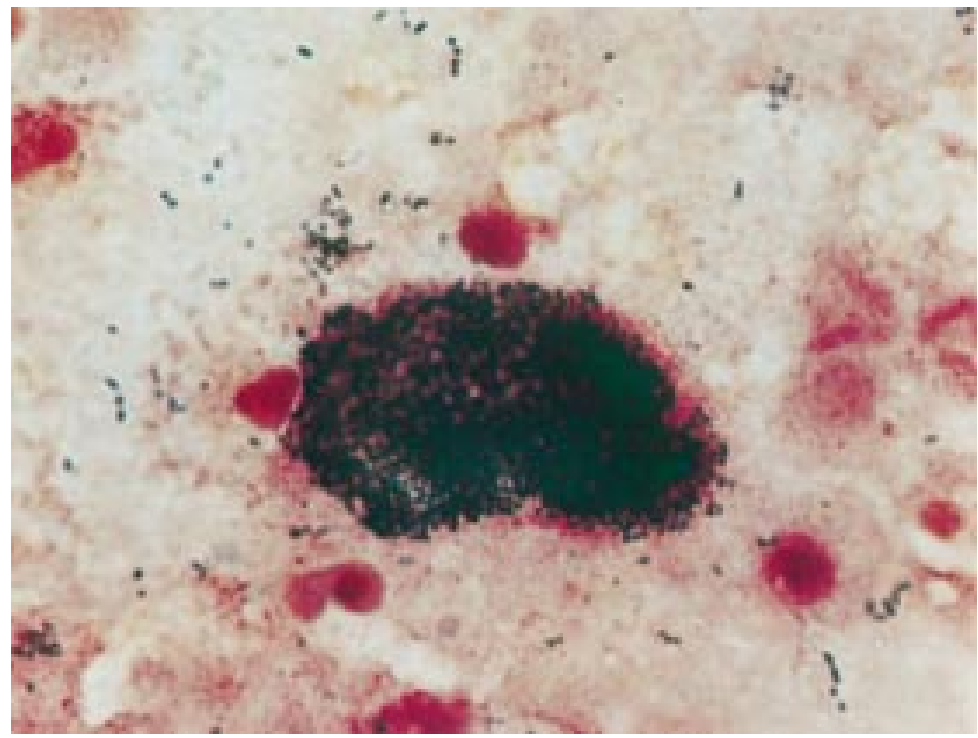

Figure 2 Gram stain of liver biopsy showing granule of Gram positive cocci with surrounding erythematous matrix (oil immersion, 69x).

Colonoscopy showed diverticulosis, though no pericolonic collection was noted on CT. The patient responded to treatment and follow up CT revealed nearly complete resolution of the hepatic lesions. Eight months after discharge, the patient is stable and asymptomatic.

\section{Discussion}

In 1908 Splendore described a biopsy with sporotrichum that was surrounded by an eosinophilic coating. He thought (erroneously) that it was a new species of sporotrichum. In 1932 Hoeppli reported radiating eosinophilic structures around schistosomes in rabbits, which he thought were secretions from the miracidia. ${ }^{1}$ Subsequent descriptions refer to the Splendore-Hoeppli phenomenon, which may appear as radiating eosinophilic spokes or as thick eosinophilic rings. The SplendoreHoeppli phenomenon has been reported in association with a variety of fungal and parasitic infections (especially by helminths and schistosoma eggs) and is particularly striking in actinomycosis, mycetoma, and botryomycosis. It is also seen around silk sutures. ${ }^{1}$

The eosinophilic deposits are thought to represent antigen-antibody precipitates. Immunoglobulin and the third component of complement have been identified in the eosinophilic matrix. In addition, there may be a contribution of (a) cellular debris from plasma cells, macrophages, lymphocytes, and eosinophils, and (b) eosinophil granule major basic protein, which constitutes the core of the granule and is toxic to helminths and mammalian cells in vitro. ${ }^{2-4}$

Our patient's Splendore-Hoeppli phenomenon developed around his botryomycotic granules. Botryomycosis describes conglomerates of bacteria in the form of granules. These granules may resemble the sulphur granules of actinomycosis, which are also masses of microorganisms embedded in a matrix. The term botryomycosis was coined by Rivolta in 1870, referring to the grape-like appearance of the granules (botryo) and the erroneously presumed fungal aetiology (mycosis). ${ }^{5}$ The usual aetiology of botryomycosis is staphylococcus, although many aerobic and anaerobic bacteria have been implicated. ${ }^{6}$ The development of botryomycosis may be facilitated by immunosuppression as it has been associated with diabetes, immunoglobulin deficiency, cutaneous anergy, corticosteroid treatment, and AIDS. ${ }^{367}$ Its pathogenesis might also depend on the inoculum size of the infecting agent, virulence of the infecting strain of bacterium, and the presence of foreign bodies. ${ }^{6}$

In our patient, the Splendore-Hoeppli phenomenon was associated with botryomycosis. The immunoglobulin component of the eosinophilic matrix presumably represents a localised attempt at containment on the part of the host. Whether this degree of immunological responsiveness is ultimately helpful or harmful to the host remains to be elucidated.

1 Binford CH, Connor DH. Pathology of tropical and extraordinary diseases. Washington DC: Armed Forces Institute of Pathology, 1976.

2 Kephart GM, Andrade ZA, Gleich GJ. Localization of eosinophil major basic protein on two eggs of Schistosoma mansoni in human pathologic tissue. Am $\mathcal{f}$ Pathol mansoni in hum

3 Patterson JW, Kitces EN, Neafie RC. Cutaneous botryomycosis in a patient with acquired immunodeficiency syndrome. F Am Acad Dermatol 1987;16:238-42.

4 Fitzpatrick TB, Eisen AZ, Wolff K, et al. Dermatology in genral medicine. New York: McGraw-Hill, 1993.

5 Bishop GF, Grier KE, Horwitz DA. Pseudomonas botryomycosis. Arch Dermatol 1976;112:1568-70.

6 Brunken RC, Lichon-Chao N, Van Den Broek H. Immunologic abnormalities in botryomycosis. $\mathcal{f} \mathrm{Am}$ Acad Dermatol 1983;9:428-34

7 Schlossberg D, Keeney GE, Lifton LJ, et al. Anaerobic botryomycosis. $\mathcal{F}$ Clin Microbiol 1980;11:184-5. 